\title{
DEVELOPMENT OF DENSE CERAMIC MEMBRANES FOR METHANE CONVERSION*
}

\author{
U. Balachandran, J. T. Dusek, P. S. Maiya, B. Ma, and R. L. Mieville \\ Energy Technology Division \\ Argonne National Laboratory \\ Argonne, IL 60439
}

RECEIVFD

JAN 301995

M. S. Kleefisch, C. A. Udovich, and T. H. Fleisch
Amoco Exploration/Production
Naperville, IL 60566

A. C. Bose

U.S. Department of Energy

Pittsburgh Energy Technology Center

Pittsburgh, PA 15236

June 1995

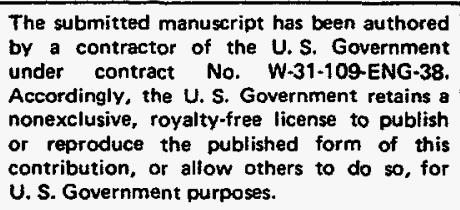

\begin{abstract}
DISCLAIMER
This report was prepared as an account of work sponsored by an agency of the United States Government. Neither the United States Government nor any agency thereof, nor any of their employees, makes any warranty, express or implied, or assumes any legal liability or responsibility for the accuracy, completeness, or usefulness of any information, apparatus, product, or process disclosed, or represents that its use would not infringe privately owned rights. Reference herein to any specific commercial product, process, or service by trade name, trademark, manufacturer, or otherwise does not necessarily constitute or imply its endorsement, recommendation, or favoring by the United States Government or any agency thereof. The views and opinions of authors expressed herein do not necessarily state or reflect those of the United States Government or any agency thereof.
\end{abstract}

Submitted to the 4th International Natural Gas Conversion Symposium, Kruger National Park, South Africa, November 19-23, 1995.

*Work at ANL is supported by the U.S. Department of Energy, Pittsburgh Energy Technology Center, under Contract W-31-109-Eng-38.

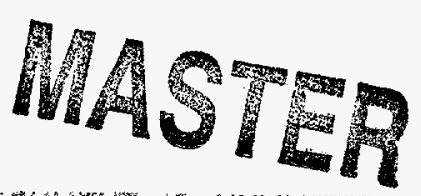


Development of dense ceramic membranes for methane conversion*

U. Balachandran, J. T. Dusek, P. S. Maiya, B. Ma, and R. L. Mieville;a

M. S. Kleefisch, C. A. Udovich, and T. H. Fleisch;b and A. C. Bosec

aArgonne National Laboratory, 9700 South Cass Avenue, Argonne, IL 60439, USA

bAmoco Exploration/Production, Naperville, Il 60566, USA

cU.S. Dept. of Energy, Pittsburgh Energy Technology Center, Pittsburgh, PA 15236, USA

The most significant cost associated with partial oxidation of methane to syngas is that of the oxygen plant. In this paper, we offer a technology, based on dense ceramic membranes, that uses air as the oxidant for methane conversion reactions, thus eliminating the need for the oxygen plant. Certain ceramic materials exhibit both electronic and ionic conductivities (of particular interest is oxygen-ion conductivity). These materials transport not only oxygen ions (functioning as selective oxygen separators) but also electrons back from the reactor side to the oxygen/reduction interface. No external electrodes are required, and, if the driving potential of transport is adequate, the partial oxidation reactions should be spontaneous. Such a system will operate without an externally applied potential. Oxygen is transported across the ceramic material in the form of oxygen ions, not oxygen molecules.

Recent reports in the literature suggest that dense ceramic membranes made of these mixed conductors can successfully separate oxygen from air at flux rates that could be considered commercially feasible. Thus, these membranes have the potential to improve the economics of methane conversion processes [1-5].

In principle, the dense ceramic materials can be shaped into hollow-tube reactors, in which air passes over the outside of the membrane and methane flows through the inside. The surfaces can also be reversed. The membrane is permeable to oxygen at high temperatures, but not to nitrogen or other gases. Thus, only oxygen from air can be transported through the membrane to the inside of the reactor surface, where it reacts with methane. Other geometric forms, such as honeycombs or corrugations, of the reactor are possible and can provide substantially greater surface areas for reaction [6].

\section{EXPERIMENTAL}

Several La-Sr-Fe-Co mixed oxides (SFCs) of differing stoichiometry were prepared by solid-state reaction of the constituent cationic salts. In this paper, we consider only two mixed oxides: SFC-1, which has the formula $\mathrm{Sr}_{1} \mathrm{Fe}_{0.2} \mathrm{Co}_{0.8} \mathrm{O}_{\mathrm{x}}$ and is a perovskite, previously studied and described by Teroaka et al. [1,2]; and SFC-2, which has a stoichiometry of

*Work at ANL is supported by the U.S. Department of Energy, Pittsburgh Energy Technology Center, under Contract W-31-109-Eng-38. 
$\mathrm{Sr}_{1} \mathrm{Fe}_{1} \mathrm{Co}_{0.5} \mathrm{O}_{\mathrm{x}}$ and a unique structure that is not a perovskite [7]. SFC-2 is the material we currently prefer and is the focus of most of this study. In the preparation of these mixed oxide ceramics, appropriate amounts of $\mathrm{La}\left(\mathrm{NO}_{3}\right)_{3}, \mathrm{SrCO}_{3}, \mathrm{Co}\left(\mathrm{NO}_{3}\right) 2.6 \mathrm{H}_{2} \mathrm{O}$, and $\mathrm{Fe}_{2} \mathrm{O}_{3}$ were mixed and milled in isopropanol with $\mathrm{ZrO}_{2}$ media for $\approx 15 \mathrm{~h}$. When dry, the mixtures were calcined in air at $\approx 850^{\circ} \mathrm{C}$ for $\approx 16 \mathrm{~h}$, with intermittent grinding. After final calcination, we ground the powder with an agate mortar and pestle to an average particle size of $\approx 7 \mu \mathrm{m}$. The resulting powders were characterized by X-ray diffraction (XRD), scanning electron microscopy (SEM), and thermal analysis; they were also analyzed for particle-size distribution.

The powder for the study was made into a slip that contained a solvent, dispersant, binder, and plasticizer. The role of each additive has been described in an earlier publication [8]. Membrane tubes were fabricated by extrusion of the slip to an outside diameter of $\approx 6.5 \mathrm{~mm}$, lengths up to $\approx 30 \mathrm{~cm}$, and wall thicknesses of $0.25-1.20 \mathrm{~mm}$. After extrusion, the tubes were sintered. The sintered tubes were characterized by SEM and XRD and then used in our partial-oxidation studies to transport oxygen for the generation of syngas. Sintered rectangular bar samples were used to measure mechanical properties. Sintered pellet samples were prepared for measuring conductivity and diffusion.

The tubes were evaluated for performance in a quartz reactor system, shown in Fig. 1. The quartz reactor supports the ceramic membrane tube with hot Pyrex seals. This design allows the ceramic tube to be in an isothermal environment. To facilitate reactions and equilibration of gases in the reactor, an $\mathrm{Rh}$-based reforming catalyst $(\approx 1 \mathrm{cc})$ is loaded adjacent to the tube. A gold wire mesh is wrapped around the tube to prevent solid-state reactions between the catalyst and the ceramic. Both the feed gas (generally $80 \%$ methane, $20 \%$ argon) and the effluents were analyzed by gas chromotography.

Mechanical properties of the finished material were measured by conventional methods, i.e., bulk density was measured by the Archimedes principle; flexural strength, in a four-point bending mode; fracture toughness, by a single-edge notch method [9]; and Young's modulus, shear modulus, and Poisson ratio, by ultrasonic methods [10]. Thermal expansion coefficients were measured in a dilatometer. Conductivities were measured by a four-probe method with a blocking electrode of yttria-stabilized zirconia for the oxygen-ion conduction [11]. Oxygen diffusion coefficients were measured by a time relaxation method. The sample was subjected to a sudden change in oxygen partial pressure and ionic conductivity was monitored as a function of time and temperature [12].

\section{RESULTS AND DISCUSSION}

Tubes of SFC -1 survived only a few minutes when used as a conversion reactor at $850^{\circ} \mathrm{C}$; they then broke into several pieces. XRD patterns of the original samples of SFC-1 were recorded at $850^{\circ} \mathrm{C}$ in $\mathrm{Ar}-\mathrm{O}_{2}$ gas mixtures. The phase behavior of SFC-1 in 1 and $20 \% \mathrm{O}_{2}$ is shown in Fig. 2. In an oxygen-rich $\left(20 \% \mathrm{O}_{2}\right)$ atmosphere, the material was a cubic perovskite. However, once the oxygen partial pressure was lowered below $5 \%$, the cubic phase transformed to an oxygen-vacancy-ordered phase.

New peaks appeared in the XRD pattern, as seen in Fig. $2\left(1 \% \mathrm{O}_{2}\right)$. It is important to note that this material expanded substantially after the phase transition; this can be seen from the change in the position of the Bragg peak near $32^{\circ}$. Evidently, this peak in the oxygen-vacancyordered phase (in $1 \% \mathrm{O}_{2}$ ) shifted to the low-angle (larger d-spacing) side of the corresponding peak in the cubic perovskite phase (in $20 \% \mathrm{O}_{2}$ ). 


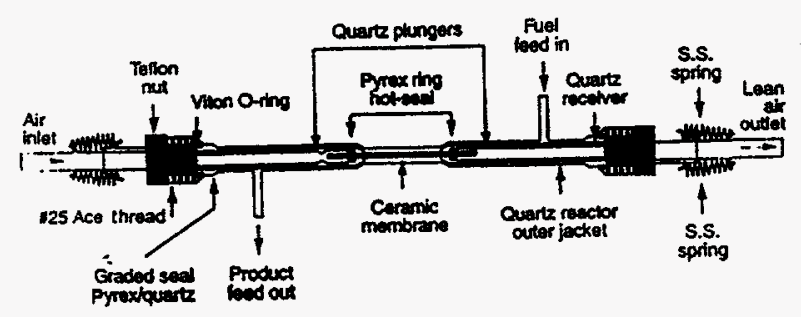

Figure 1. Schematic diagram of ceramic membrane reactor.

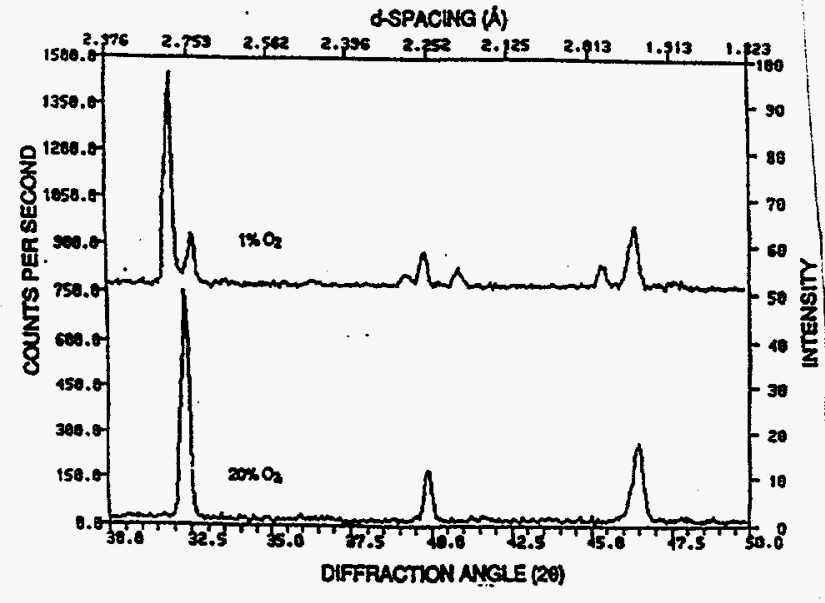

Figure 2. XRD of $\mathrm{SFC}-1$ at $850^{\circ} \mathrm{C}$ in $1 \%$ and $20 \% \mathrm{O}_{2}$ (balance is $\mathrm{Ar}$ ).

Detailed thermogravimetric analysis (TGA) [13] showed that the oxygen content $\mathrm{x}$ of the SFC-1 sample in $1 \% \mathrm{O}_{2}$ was $\approx 0.1$ lower than that in a sample in $20 \% \mathrm{O}_{2}$. Dependence of the unit cell volume on oxygen content of the sample has been established by comparing lattice parameters. For example, the volume of the primitive perovskite cell $\mathrm{Vp}$ is $57.51 \AA^{3}$ for $x=2.67$ and $59.70 \AA^{3}$ for $x=2.48$. These results show that this material expands as oxygen is removed. Such behavior suggests that an electronic effect is predominant in influencing the specific volume; otherwise, a simple size effect would cause the lattice to shrink. By linear interpolation of the above results, we predict that a decrease in $\mathrm{x}$ of 0.1 will result in an increase in $\mathrm{Vp}$ of $\approx 2 \%$.

Both XRD results and TGA data [13] give a clear picture of the state of SCF-1 under reaction conditions. When the membrane tube is operating, high oxygen pressure is maintained inside the tube and low oxygen pressure is maintained outside the tube. Before the tube is brought up to high temperature, oxygen distribution is uniform. Upon heating, the tube material begins to lose oxygen that was incorporated during the fabrication process. Moreover, the material on the outer wall loses more oxygen than the material on the inner wall. As a result, a stable oxygen gradient is generated between the inner and outer walls. It follows that the material, depending on its location in the tube, may contain different phase constituents. It is probable that the outer zone of lower oxygen content contains more ordered oxygen vacancies and hence is less permeable to oxygen.

The major factor that can cause tube fracture appears to be lattice mismatch between the materials on the inner and outer walls of the tube. The difference in composition between the inner and outer walls leads to an expansion of $2 \%$, which is equivalent to thermal expansion caused by a $333^{\circ} \mathrm{C}$ temperature increase.

In comparison, SFC-2 exhibited a remarkable structural stability at high temperature, as shown in Fig. 3. No phase transition was observed in this material as oxygen partial pressure was changed. Furthermore, the Bragg peaks stayed at the same position regardless of the oxygen partial pressure of the atmosphere. The physical and mechanical properties of SFC-2 are listed in Table 1.

The Weibull modulus was 15 , as measured by plotting the probability of failure vs. flexural strength, indicating only moderate scatter in the strength data. Measured room-temperature properties were used to develop failure criteria for the membranes under actual reaction 


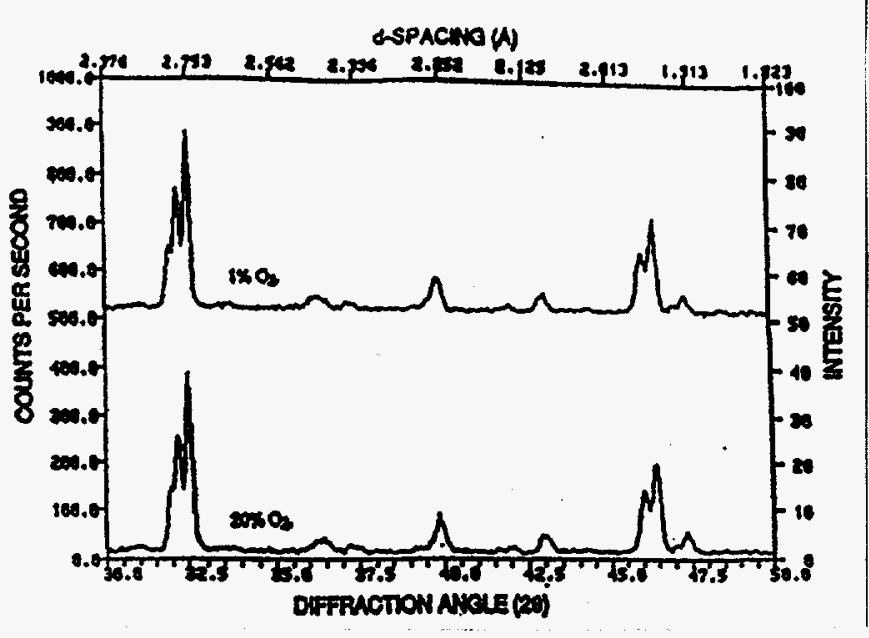

Figure 3. XRD of SFC-2 at $850^{\circ} \mathrm{C}$ in $1 \%$ and $20 \% \mathrm{O}_{2}$ (balance is $\mathrm{Ar}$ ).

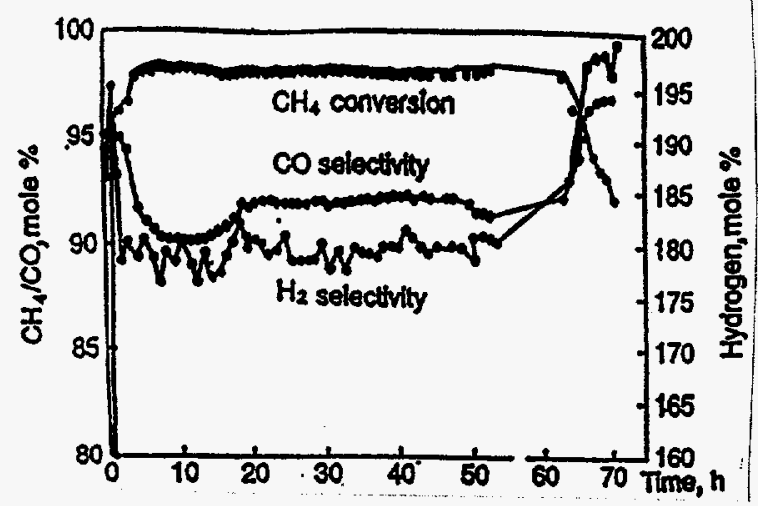

Figure 4. Methane conversion and $\mathrm{CO}$ and $\mathrm{H}_{2}$ selectivities in SFC-2 membrane reactor with reforming catalyst. Conditions: feed, $80 \% \mathrm{CH}_{4}, 20 \% \mathrm{Ar}$; flow, $2.5 \mathrm{~cm}^{3} / \mathrm{min}$; temperature, $850^{\circ} \mathrm{C}$; pressure $1 \mathrm{~atm}$; surface area, $10 \mathrm{~cm}^{2}$.

Table 1

Physical and mechanical properties of SFC-2

\begin{tabular}{lc}
\hline \multicolumn{1}{c}{ Property } & Value \\
\hline Bulk density & $4.81{\mathrm{~g} . \mathrm{cm}^{-3}}^{-3}$ \\
Percent of theoretical density & 93 \\
Coefficient of thermal expansion & $14 \times 10^{-6} /{ }^{\circ}\left(200-800^{\circ} \mathrm{C}\right)$ \\
Flexural strength & $120.4 \pm 0.06 \mathrm{MPa}$ \\
Fracture toughness & $2.04 \pm 0.06 \mathrm{MPa} \sqrt{\mathrm{m}}$ \\
Young's modulus & $124 \pm 3 \mathrm{GPa}$ \\
Shear modulus & $48 \pm 2 \mathrm{GPa}$ \\
Poisson ratio & $0.30 \pm 0.01$ \\
\hline
\end{tabular}

conditions in a plant where methane is expected to be at higher pressures. The computed allowable external pressure for SFC-2 was $200 \mathrm{MPa}$ at a tube wall thickness of $1 \mathrm{~mm}$ (the dependence of pressure on thickness is linear). These results suggest that this ceramic material can withstand the reasonable stresses that might occur in a commercial reactor. Tubes made of this material, unlike those made of SFC-1, are not expected to fracture under reactor conditions.

The electronic and ionic conductivities of SFC-2 were 10 and $7 \mathrm{~s} \mathrm{~cm}$, respectively. When compared with other materials of this type, SFC-2 is unique in that the ratio of ionic to electronic conductivity is close to 1 [12]. Furthermore, limited SFC-2 diffusion data, obtained by the time relaxation method [13], indicate that the transport of oxygen ions is associated with 
an activation energy of $0.89 \mathrm{eV}$. This value is consistent with the high diffusion coefficient of $9 \times 10^{-7} \mathrm{~cm}^{2} \mathrm{~s}^{-1}$ at $900^{\circ} \mathrm{C}$.

Performance in generating syngas is demonstrated in Fig. 4, which shows conversion data obtained with an SFC-2 membrane tube operated at $850^{\circ} \mathrm{C}$ for $\approx 70 \mathrm{~h}$. As shown, methane conversion efficiency is $>98 \%$, and $\mathrm{CO}$ selectivity is $90 \%$. Measured $\mathrm{H}_{2}$ yield is about twice that of $\mathrm{CO}$ as expected.

The role of the catalyst in the transport of oxygen across the membrane of an SFC-2 tube was tested without the reforming catalyst. The results from a run of $\approx 350 \mathrm{~h}$ are shown in Fig 5. The feed gases are the same as before. In the absence of a catalyst, the oxygen that was transported through the membrane reacted with methane and formed $\mathrm{CO}_{2}$ and $\mathrm{H}_{2} \mathrm{O}$. As seen in Fig. 5 , methane conversion efficiency was $\approx 35 \%$ and $\mathrm{CO}_{2}$ selectivity was $\approx 90 \%$. Under our operating conditions, the measured oxygen flux was $\approx 0.3 \mathrm{std} \mathrm{cm}^{3} / \mathrm{cm}^{2} / \mathrm{min}$.

Further confirmation of the stability of this membrane tube is shown in Fig. 6, which shows reactor results over a period of $1000 \mathrm{~h}$. The feed during this period was a typical mixture expected in a commercial recycle feed, namely methane, $\mathrm{CO}, \mathrm{CO}_{2}$, and $\mathrm{H}_{2}$. Throughout the run, methane conversion was high. Variations in the feed flow rate caused fluctuations in the conversion. A small decline in oxygen permeation was observed. However, this high oxygen flux is consistent with the high diffusion coefficient of $9 \mathrm{x}$ $10^{-7} \mathrm{~cm}^{2} \mathrm{~s}^{-1}$ that was measured by the time relaxation method [12].

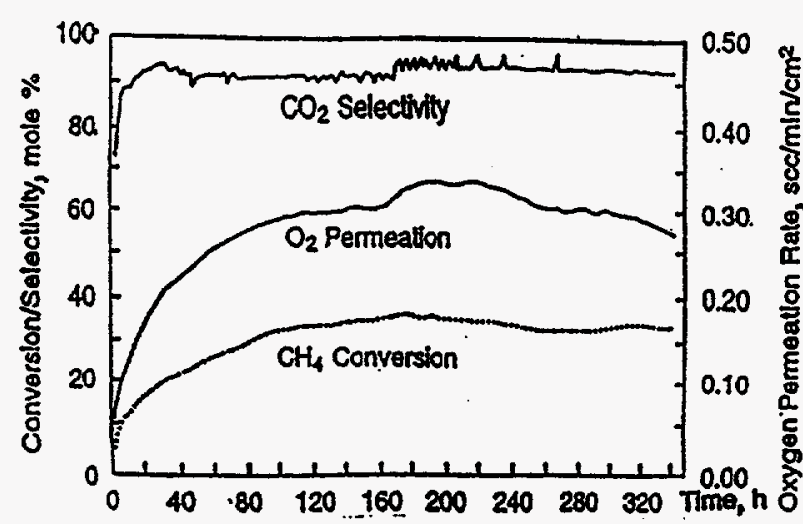

Figure 5. Methane conversion and $\mathrm{CO}_{2}$ selectivity and $\mathrm{O}_{2}$ permeation in SFC-2 membrane reactor without reforming catalyst. Conditions: same as in Fig. 4.

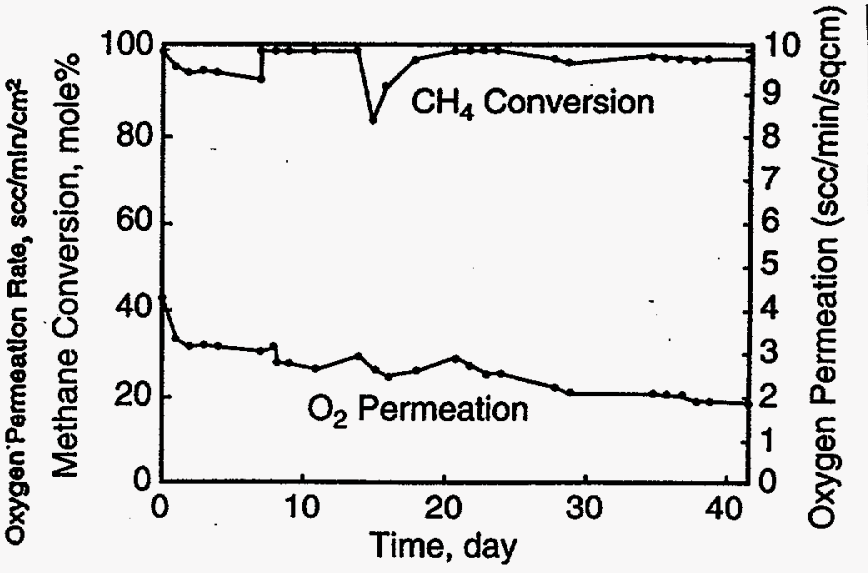

Figure 6. Methane conversion and $\mathrm{CO}$ and $\mathrm{H}_{2}$ selectivities and $\mathrm{O}_{2}$ permeation in $\mathrm{SFC}-2$ membrane reactor with reforming catalyst. Conditions: mixed feed, $20 \mathrm{~cm}^{3} / \mathrm{min}$; temperature, $900^{\circ} \mathrm{C}$; pressure $1 \mathrm{~atm}$; membrane surface area, $8 \mathrm{~cm}^{2}$.

\section{CONCLUSIONS}

Mixed-conducting ceramic materials have been produced from mixed-oxide systems of the $\mathrm{Sr}-\mathrm{Fe}-\mathrm{Co}-\mathrm{O}$ (SFC) type, in the form of tubes and bars. Thermodynamic stability of the tubes was studied as a function of oxygen partial pressure by high-temperature XRD. Mechanical properties of SFC-2 were measured and found to be adequate for a reactor. Measured electronic and ionic conductivities showed that SFC-2 is unique in that the ratio of ionic to electronic conductance is close to 1 . 
The performance of the membrane tubes was good only when the tubes were made of SFC-2. Fracture of other SFC tubes was the consequence of an oxygen gradient that introduced a volumetric lattice difference between the inner and outer walls. SFC-2 tubes provided methane conversion efficiencies of $>99 \%$ in a reactor. These tubes have operated for $>1000 \mathrm{~h}$.

\section{REFERENCES}

1. Y. Teraoka, H. M. Zhang, S. Furukawa, and N. Yamozoe, Chem. Lett. (1985) 1743.

2. Y. Teraoka, T. Nobunaga, and N. Yamazoe, Chem. Lett. (1988) 503.

3. U. Balachandran, S. L. Morissette, J. J. Picciolo, J. T. Dusek, R. B. Poeppel, S. Pei, M. S. Kleefisch, R. L. Mieville, T. P. Kobylinski, and C. A. Udovich, in Proc. Intl. Gas Research Conf. (H. A. Thompson, ed.) pp. 565-573, Government Institutes, Inc., Rockville, MD, 1992.

4. T. J. Mazanec, T. L. Cable, and J. G. Jr. Frye, Solid State Ionics, 111 (1992) 53.

5. T. L. Cable, European Patent EP 0438902 A2, July 31, 1991.

6. T. D. Claar, D. E. Busch, and J. J. Picciolo, US Patent No. 4883497 (1989).

7. U. Balachandran, M. Kleefisch, T. P. Kobylinski, S. L. Morissette, and S. Pei, International Patent WO94/24065, Oct. 1994.

8. U. Balachandran, J. T. Dusek, S. M. Sweeney, R. B. Poeppel, R. L. Mieville, P. S. Maiya, M. S. Kleefisch, S. Pei, T. P. Kobylinski, and C. A. Udovich, Amer. Ceram. Soc. Bull., 74 (1995) 71.

9. W. F. Brown, Jr. and J. E. Strawley, ASTM STP 410, Philadelphia, PA, 1967.

10. J. Kraütkramer and H. Kraütkramer, Ultrasonic Testing of Materials (Springer-Verlag, NY, 1983).

11. B. Ma, J.-H. Park, U. Balachandran, and C. U. Segre, "Electronic/Ionic Conductivity and Oxygen Diffusion Coefficient of the $\mathrm{Sr}-\mathrm{Fe}-\mathrm{Co}-\mathrm{O}$ System," Materials Research Society Spring Meeting, San Francisco, CA, April 17-21, 1995.

12. B. Ma, U. Balachandran, J.-H. Park, and C. U. Segre, submitted to Solid State Ionics, 1995.

13. S. Pei, M. S. Kleefisch, T. P. Kobylinski, J. Faber, C. A. Udovich, V. ZhangMcCoy, B. Dabrowski, U. Balachandran, R. L. Mieville, and R. B. Poeppel, Catal. Lett., 30 (1995) 201. 